\title{
Evaluation of pulsed Nd:YAG laser posterior hyaloidotomy as an emergency treatment for blinding premacular subhyaloid hemorrhage
}

This article was published in the following Dove Press journal:

Open Access Emergency Medicine

12 May 2011

Number of times this article has been viewed

\author{
Hazem A Hazem' \\ Tarek A Shazly ${ }^{1,2}$ \\ 'Department of Ophthalmology, \\ Assiut University Hospital, Assiut, \\ Egypt; '2Department of Ophthalmology, \\ Massachusetts Eye and Ear Infirmary, \\ Harvard Medical School, Boston, \\ MA, USA
}

Purpose: This study aimed to evaluate the benefits of Nd:YAG laser posterior hyaloidotomy as a method allowing rapid drainage of subhyaloid hemorrhage into the vitreous gel.

Design: Nonrandomized, prospective, interventional, controlled case series.

Methods: Nd:YAG laser posterior hyaloidotomy was performed in four eyes of three patients with premacular subhyaloid hemorrhage. The etiologies were bleeding tendency, proliferative diabetic retinopathy, and idiopathic. Four eyes of four patients with premacular subhyaloid hemorrhage were managed conservatively. The etiologies were proliferative diabetic retinopathy and Valsalva retinopathy.

Results: A rapid resolution of subhyaloid hemorrhage with improvement of visual acuity was achieved in all patients treated with Nd:YAG laser posterior hyaloidotomy, without evidence of damage to the retina or choroid. With regard to the conservatively managed eyes, there was a tendency towards slow spontaneous absorption of hemorrhage during the follow-up period. Conclusion: Nd:YAG laser posterior hyaloidotomy was a safe and effective procedure for rapid resolution of premacular subhyaloid hemorrhage, allowing rapid restoration of visual acuity, visualization of the underlying retina, expedited access for macular photocoagulation and avoidance of vitrectomy.

Keywords: retinal hemorrhage, vitreous hemorrhage, laser surgery, proliferative diabetic retinopathy

\section{Introduction}

Patients with premacular subhyaloid hemorrhage present with sudden profound loss of vision. Although spontaneous resolution is expected in most cases, it occurs in a slow, frustrating, and sometimes incapacitating manner to the patient especially in bilateral cases or in one eyed patients. It can result from a variety of conditions such as Valsalva retinopathy, macroaneurysms, proliferative diabetic retinopathy (PDR), retinal vein occlusion, bleeding tendencies, and may be idiopathic. ${ }^{1}$

$\mathrm{Nd}$ :YAG laser can produce a defect in the posterior hyaloid/internal limiting membrane ${ }^{2}$ allowing rapid diffusion of hemorrhage into the vitreous gel thus clearing the visual axis and allowing faster absorption of blood. This study aimed to assess the benefit of pulsed Nd:YAG laser posterior hyaloidotomy in patients with premacular subhyaloid hemorrhage of variable etiologies compared with those patients who were managed conservatively.

\section{Methods}

Pulsed Nd:YAG laser posterior hyaloidotomy was used in four eyes of three patients with premacular subhyaloid hemorrhage. The VISULAS YAG II plus; Zeiss system 
was used. After full pupillary dilatation and topical anesthesia, a Goldmann contact lens was used to focus the Nd:YAG aiming beam and laser so that an opening in the posterior hyaloid membrane near the inferior edge of the subhyaloid hemorrhage could be performed, avoiding retinal blood vessels and fovea but keeping a reasonably sufficient underlying cushion of blood to shield the underlying retina. Nd:YAG laser power needed varied from $2.5 \mathrm{~mJ}$ to $7.4 \mathrm{~mJ}$ and the number of applications varied from one to five strategically placed impacts to achieve the needed aperture through the posterior hyaloid membrane.

Conservative management involved regular follow-up of the patients without intervention until spontaneous resolution of the prehyaloid hemorrhage was complete.

\section{Results}

\section{Eyes treated by $\mathrm{Nd}$ :YAG laser posterior hyaloidotomy (four eyes)}

Three out of four eyes treated with Nd:YAG laser posterior hyaloidotomy achieved rapid resolution of premacular hemorrhage with immediate trickling of blood downwards into the inferior vitreous gel. One eye showed a slower resolution over the following 2 weeks (Table 1).

\section{Case I}

A 16-year-old patient suffering a bleeding tendency presented with bilateral subhyaloid hemorrhage. Consequential Nd:YAG laser hyaloidotomy was performed in the left eye followed by the right resulting in complete clearance of both macular areas (Figure 1).

\section{Case 2}

A 49-year-old man presented with a large subhyaloid hemorrhage. A Nd:YAG laser posterior hyaloidotomy was carried out. Clearance of hemorrhage showed a retinal macroaneurysm in the temporal inferior vascular area as the underlying cause (Figure 2).

\section{Case 3}

A 57-year-old woman with proliferative diabetic retinopathy presented with left premacular subhyaloid hemorrhage that reduced visual acuity to counting fingers. A Nd:YAG laser posterior hyaloidotomy was performed, and it allowed clear visualization of the posterior pole with improvement of visual acuity to its premorbid level 20/60 (Figure 3).

\section{Conservatively managed patients}

Four patients with premacular subhyaloid hemorrhage were observed (Table 2). Two patients had gradual resolution of hemorrhage over a period of 4 weeks (cases 1 and 2). One patient had no improvement in the subhyaloid hemorrhage at 12 weeks and was lost for follow-up afterwards (case 3, Figure 4); and the other showed gradual absorption of the hemorrhage over the next 6 weeks only to end up with another subhyaloid bleed (case 4, Figure 5).

\section{Discussion}

In our series, drainage of premacular subhyaloid hemorrhage into the vitreous with an Nd:YAG laser was achieved in all four eyes treated, without any clinical evidence of damage to the underlying retina or choroid. In accordance with the results of other series, ${ }^{2-5}$ this resulted in hastened improvement of vision to normal or premorbid level. It also allowed rapid restoration of visualization of the macular region with expedited access for fluorescein angiography and macular photocoagulation.

As blood, hemoglobin, and iron have, in increasing order, a toxic effect on the retina, ${ }^{7}$ it seems fitting to drain this blood in order to prevent macular damage, especially if this can be achieved in a noninvasive way such as the Nd:YAG laser.

Clinical examination revealed no evidence of retinal or choroidal hemorrhage, or retinal pigment epithelial changes, from Nd:YAG laser treatment in any of the patients in this series. In one paper on the use of Nd:YAG laser for subhyaloid hemorrhage, 2 of 21 patients developed complications. One developed a macular hole (although no macular hole was observed in the other eye with more extended hemorrhage that was treated as well), and the other a retinal break in a myopic eye (with retinal breaks occurring in the untreated

Table I Visual outcome in patients who received Nd:YAG laser treatment

\begin{tabular}{llllllll}
\hline Patient number & Age & Etiology & $\begin{array}{l}\text { Presenting } \\
\text { VIA }\end{array}$ & $\begin{array}{l}\text { Time to } \\
\text { treatment }\end{array}$ & $\begin{array}{l}\text { V/A at 2 weeks } \\
\text { post laser }\end{array}$ & Final VIA & Comments \\
\hline I. OD & 16 & Bleeding tendency & $20 / 400$ & 1 week & $20 / 30$ & $20 / 20$ & Figure I \\
I. OS & 16 & Bleeding tendency & $20 / 400$ & 2 weeks & $20 / 20$ & $20 / 20$ & Figure I \\
2 & 49 & Macroaneurysm & $20 / 600$ & 10 days & $20 / 20$ & $20 / 20$ & Figure 2 \\
3 & 57 & PDR & HM & 2 days & $20 / 200$ & $20 / 60^{*}$ & - \\
\hline
\end{tabular}

Abbreviations: V/A, visual acuity; HM, hand motion; PDR, proliferative diabetic retinopathy. 


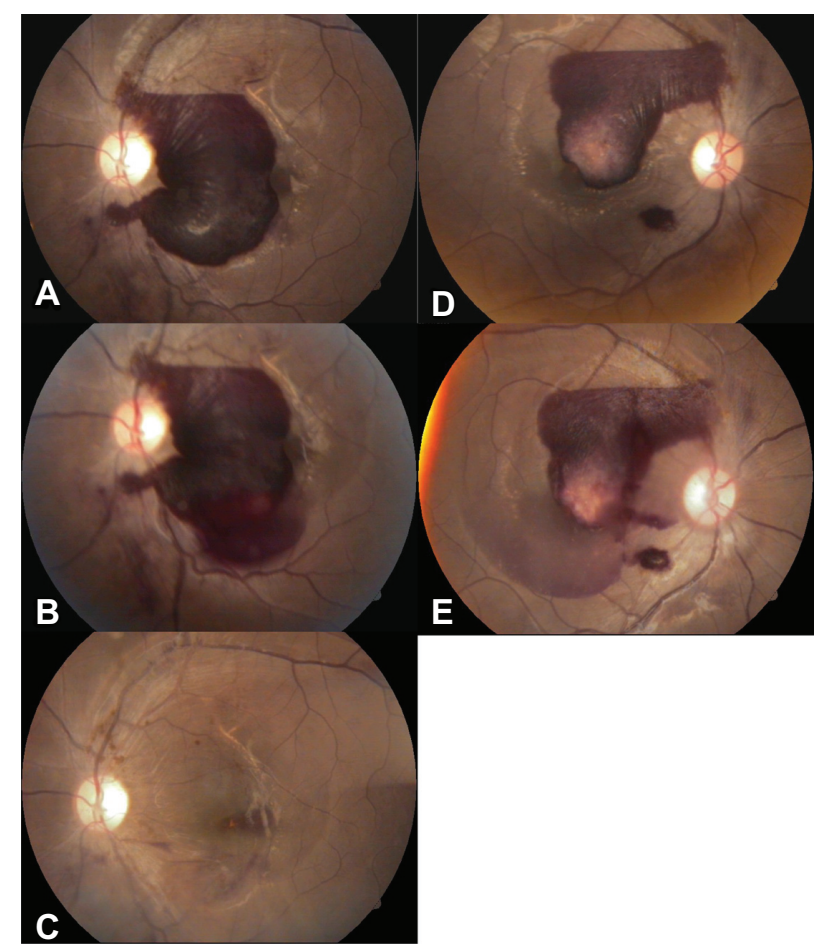

Figure I To the left: Color photograph of the fundus of the left eye of case I of the Nd:YAG laser treated group: A) At presentation; B) Immediately after Nd:YAG laser treatment; C) I week after treatment. To the right: Color photograph of the fundus of the right eye of the same case: D) At presentation; E) Immediately after Nd:YAG laser treatment.

eye as well). ${ }^{5}$ Others reported epiretinal membrane formation with internal limiting membrane wrinkling after Nd:YAG laser membranotomy in Valsalva retinopathy. ${ }^{6}$

Early vitrectomy has also been advocated for dense premacular hemorrhage due to proliferative diabetic retinopathy with the advantage of removing the hemorrhage and

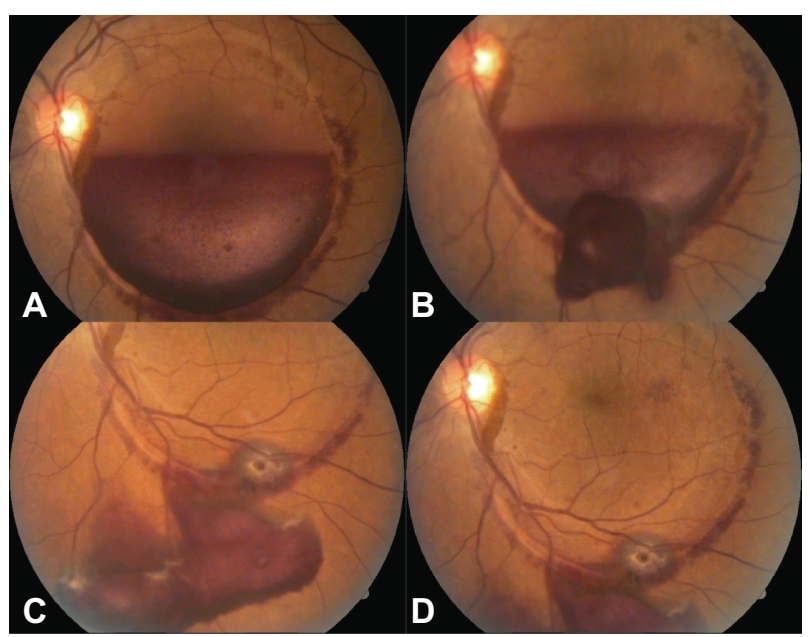

Figure 2 Color fundus photographs of case 2 of the Nd:YAG laser treated group: A) An extended premacular subhyaloid hemorrhage; B) After puncture with the Nd:YAG laser, outflow of the entrapped blood is visible; C) After about I week, all hemorrhage has drained into an inferior vitreous cistern; D) The macula is clearly exposed and a macroaneurysm in the temporal inferior vascular area is visible.

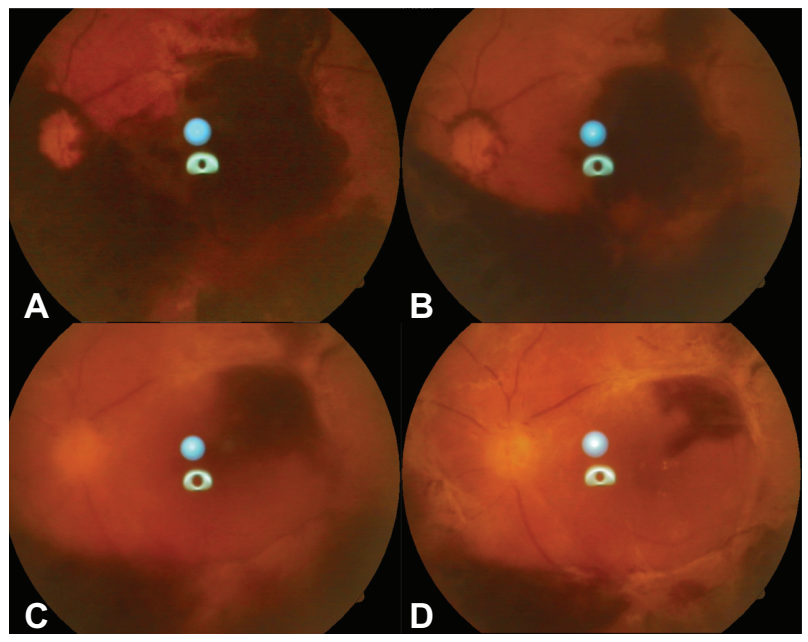

Figure 3 Color photograph of the fundus of case 3 of the Nd:YAG laser treated group: A) At presentation; B) I week after treatment by Nd:YAG laser; C) 4 weeks after treatment by Nd:YAG laser. Note increasing vitreous haze due to dispersion of blood into the vitreous gel; D) Final appearance after clearance of vitreous haze.

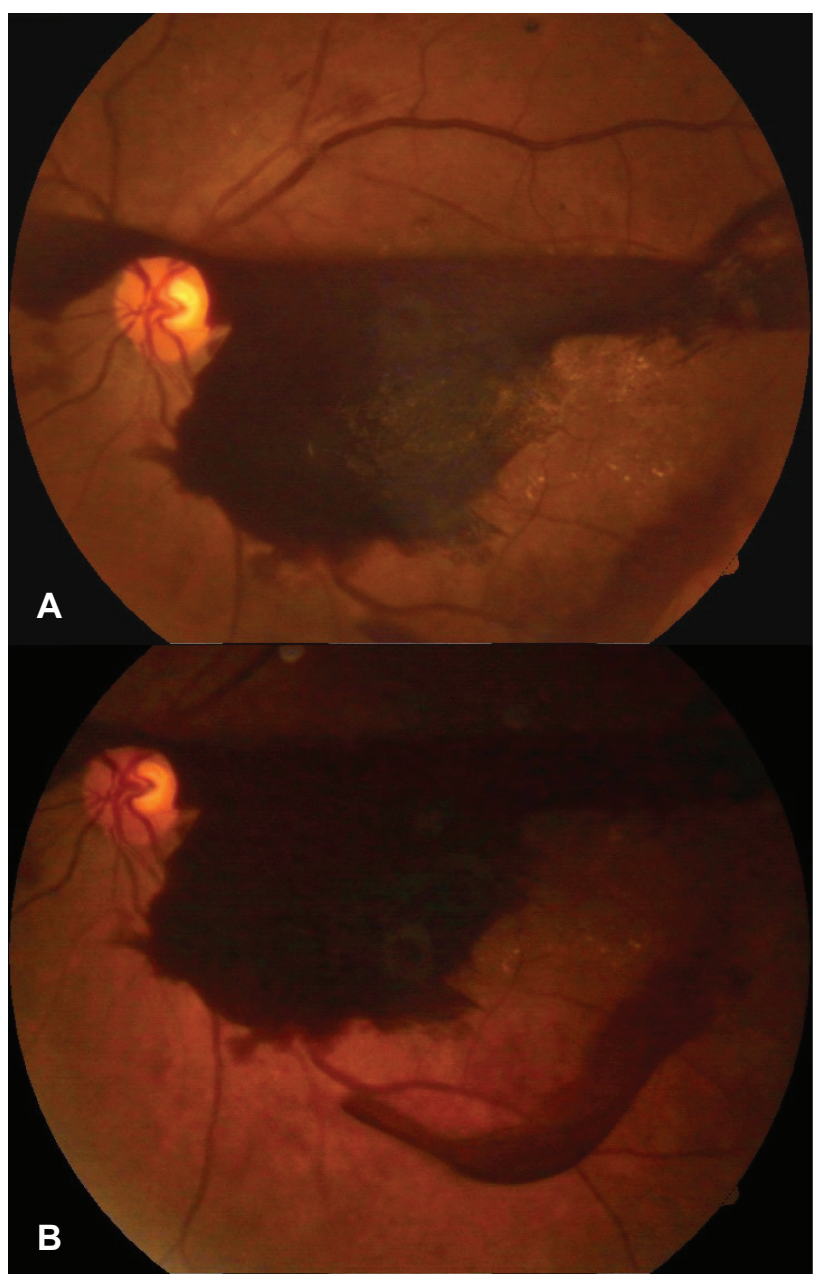

Figure 4 Color fundus photographs of case 3 of conservatively managed patients: A) At presentation; B) 12 weeks later showing almost the same amount of hemorrhage. 
Table 2 Visual outcome in conservatively managed patients

\begin{tabular}{|c|c|c|c|c|c|c|}
\hline $\begin{array}{l}\text { Patient } \\
\text { number }\end{array}$ & Age & Etiology & Presenting V/A & Final VIA & $\begin{array}{l}\text { Follow- up } \\
\text { (months) }\end{array}$ & Comments \\
\hline 1 & 62 & PDR & $20 / 400$ & $20 / / 20$ & 2 & $\begin{array}{l}\text { Final visual acuity was limited by } \\
\text { diabetic maculopathy }\end{array}$ \\
\hline 2 & 25 & Valsalva retinopathy & $20 / 200$ & $20 / 20$ & 2 & - \\
\hline 3 & 64 & PDR & HM & $\mathrm{HM}$ & 3 & See Figure 3 \\
\hline 4 & 55 & PDR & $20 / 60$ & $20 / 30$ & 2 & $\begin{array}{l}\text { The subhyaloid hemorrhage collected } \\
\text { in front of the inferior macular region } \\
\text { sparing the fovea }\end{array}$ \\
\hline
\end{tabular}

Abbreviations: VIA, visual acuity; HM, hand motion; PDR, proliferative diabetic retinopathy.

delamination of the membrane that serves as a scaffold for neovascularization. ${ }^{7-9}$

This membrane was present in both the treated and observed patients in this series confining the area of posterior vitreous detachment holding the hemorrhage that must have remained unchanged after resolution of the subhyaloid hemorrhage. Also, vitrectomy may be required after Nd:YAG

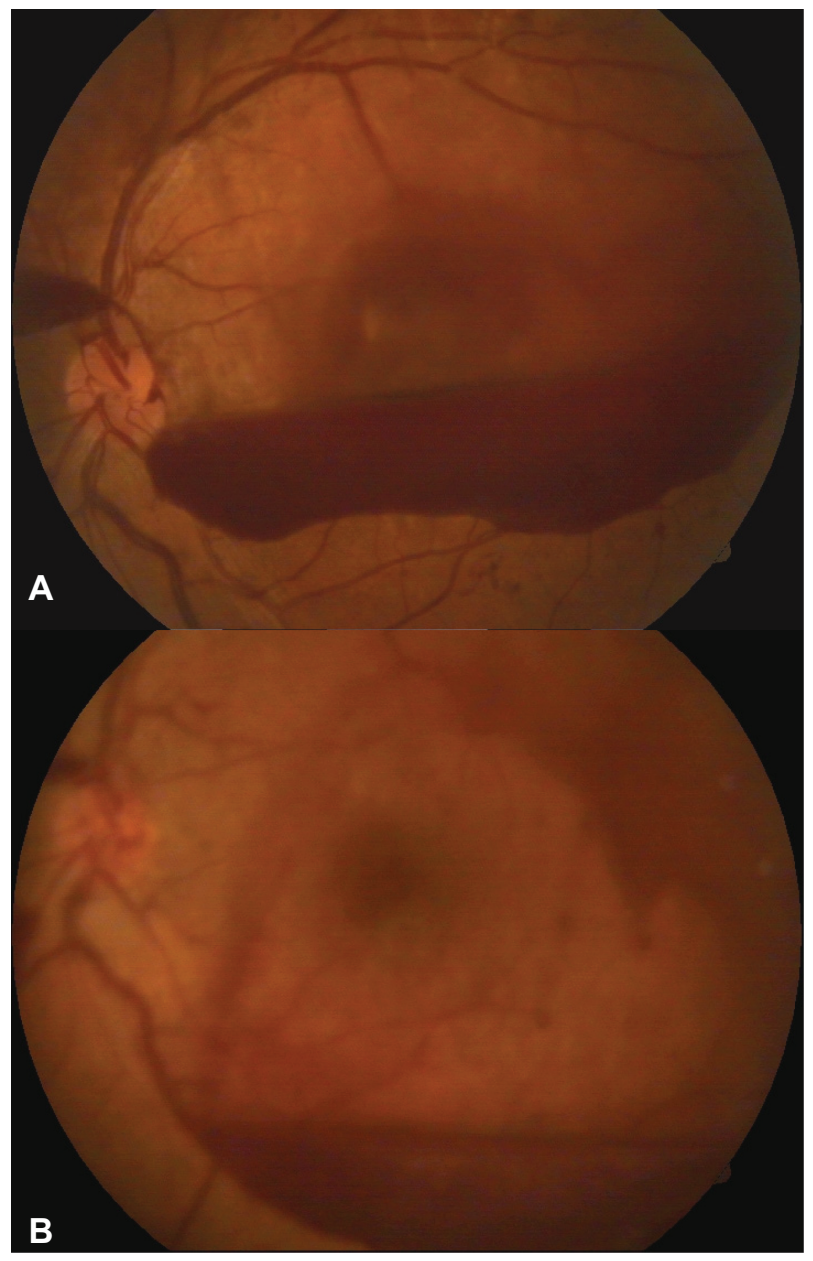

Figure 5 Color fundus photographs of case 4 of conservatively managed patients: A) At presentation; B) 10 weeks later showing recurrence of bleeding in a more inferior location after initial spontaneous absorption. laser treatment because of the persistence of dispersed blood in the central vitreous, a clotted hemorrhage that refused to drain into the vitreous despite an opening at the vitreoretinal interface, a macular hole, and a retinal detachment.

In conclusion, Nd:YAG laser hyaloidotomy is shown to be a safe and effective procedure for the treatment of recent premacular subhyaloid hemorrhage, producing rapid dispersion of blood with restoration of visual function, without a more invasive vitreoretinal procedure. This is particularly important for patients with poor vision in their fellow eye and patients requiring rapid visual rehabilitation to be able to continue working. Nevertheless, it should be used carefully with the lowest effective energy settings to avoid collateral damage to the retina. It also allows early assessment of the underlying retina, expedited access for macular photocoagulation and the avoidance of vitrectomy. If left untreated, the subhyaloid hemorrhage resolves slowly with prolonged reduction of visual function and possible toxic damage to the retina from prolonged contact with hemoglobin and iron. ${ }^{7}$ The final visual prognosis is, however, limited by the underlying cause of the subhyaloid hemorrhage and any associated retinal changes. Long-term surveillance of laser-treated cases is necessary and only randomization with deferral of treatment or vitrectomy can define benefits and disadvantages.

\section{Disclosure}

No conflicts of interest were declared in relation to this paper.

\section{References}

1. Gass JDM. Stereoscopic atlas of retinal diseases: diagnosis and treatment. 3rd ed. St Louis, MO: CV Mosby, 1987;362:560-564.

2. Raymond LA. Neodymium: YAG Laser treatment for hemorrhages under the internal limiting membrane and posterior hyaloid face at the macula. Ophthalmology. 1995;102:406-411.

3. Isaacs TW, Barry C, McAllister IL. Early resolution of premacular hemorrhage following Nd:YAG laser photodisruption of posterior hyaloid. Aust NZ J Ophthalmol. 1996;24:365-367. 
4. Iijima H, Satoh S, Tsukahara S. Nd:YAG laser photodisruption for preretinal hemorrhage due to retinal macroaneurysm. Retina. 1988;18: 430-434.

5. Ulbig MW, Mangouristas G, Rothbacher HH, Hamilton AMP, McHugh JD Long-term results after drainage of premacular subhyaloid hemorrhage into the vitreous with pulsed Nd:YAG laser. Arch Ophthalmol. 1998;116:1465-1469.

6. Alvin KH, Timothy YY, Nongnart R. Epiretinal membrane formation with internal limiting membrane wrinkling after Nd:YAG laser membranotomy in Valsalva retinopathy. Am J Ophthalmol. 2003;136:763-766.
7. Forrester JV, Grierson L, Lee WR. Vitreous membrane formation after experimental vitreous hemorrhage. Albrecht Von Graefes Arch Klin Exp Ophthalmol. 1983;212:227-242.

8. The Diabetic Retinopathy Vitrectomy Study Research Group. Early vitrectomy for severe vitreous hemorrhage in diabetic retinopathy: four year results of a randomized trial: diabetic Retinopathy Study Report 5. Arch Ophthalmol. 1990;108:958-964.

9. Shazly TA, Latina MA. Neovascular glaucoma: etiology, diagnosis and prognosis. Semin Ophthalmol. 2009 Mar-Apr;24(2):113-121.

\section{Publish your work in this journal}

Open Access Emergency Medicine is an international, peer-reviewed, open access journal publishing original research, reports, editorials, reviews and commentaries on all aspects of emergency medicine. The manuscript management system is completely online and includes a very quick and fair peer-review system, which is all easy to use.
Visit http://www.dovepress.com/testimonials.php to read real quotes from published authors. 